\title{
Knowledge of Auxiliary Healthcare Workers on Injection Safety and Biological Waste Handling in Taraba State, Nigeria
}

\author{
Article by Danung Monday Langche ${ }^{1}$, Jegede Feyisayo ${ }^{2}$, Usman Abdulrasheed ${ }^{3}$ \\ ${ }^{1}$ Ph.D. in Public Health, Texila American University, Nigeria, ${ }^{2,3}$ Federal Medical \\ Center Jalingo, Taraba State \\ E-mail: 1danungml@gmail.com, ${ }^{2}$ feyitab@yahoo.com, ${ }^{3}$ usmanurasheed@gmail.com
}

\begin{abstract}
Background: Individuals working in healthcare settings occasionally are at risk of infections as a result of exposure to certain diseases causing agents. However, in most developing countries attention on prevention is mainly focused on skilled healthcare workers (HCWs) with "neglect" of auxiliary health workers (AHWs) who may not be knowledgeable on job health hazard and carries high risk of exposure to infectious agents.

Objective: To assess knowledge of auxiliary healthcare workers on injection safety and biological waste handling as well as attitude towards post exposure prophylaxis in the event of any exposure.

Methods: A descriptive cross-sectional study conducted among AHWs on knowledge on injection safety and biological waste handling in June 2016. Participants included ward orderlies (WOs), lab attendants (LAs), compound laborers (CLs), theater attendants (TAs) and laundry personnel (LPs) randomly selected. A semi structured questionnaire administered to consented respondents. Data was presented as descriptive analysis and percentage compared using Chi-square test with significant level 0.05 at 95\% Confidence interval.

Results: A total of 68 auxiliary healthcare workers consisting of male $44.1 \%(n=30)$ and female $55.9 \%(n=38)$ were interviewed. Respondent's mean $\pm(S D)$ age was $31 \pm 5.30$ years and ranged from 27- 55 years. Knowledge on injection safety and biological waste handling among AHWs showed (WOs) 42/68 (61.7\%), (LAs) 5/68 (7.4\%), (CLs) 9/68 (13.2\%), (TAs) 5/68 (7.4\%) and (LWs) 7/68 (10.3\%). A significant difference in knowledge on injection safety and biological waste handling among AHWs was observed. $\left(X^{2}=1.56\right.$, $d f 4$, critical value 9.488 at $95 \%$ confidence level.

Conclusion: There is low level of knowledge on needle stick injury (NSI), biological waste handling and poor attitude towards PEP among auxiliary healthcare workers in GH Wukari and GH Zing.
\end{abstract}

Keywords: Knowledge, Auxiliary, Biological, Injection, Waste, Safety

\section{Background and introduction}

It is no longer news that individuals working in healthcare settings occasionally falls victim of certain illness as a result of exposure to certain disease causing agents in the cause of their work. As defined by the World Health Organization (WHO - 2015), "occupational health deals with all aspects of health and safety in the workplace and has a strong focus on primary prevention of hazards ${ }^{1}$. In terms of healthcare providers, disorders could occur as a result of work-related exposure to biological, chemical and physical disease causing agents. Exposure could lead to a point where usual physiological mechanisms are affected and with resultant impairment of the personnel's health ${ }^{1}$.

Low cadre Hospital personnel include but not limited to ward orderlies, Laboratory attendants, waste handlers (compound laborers) and laundry workers. These categories of staffs have potentials of being exposed to biological waste via needle-stick injuries with attendant consequences. Well planned hazard control mechanisms and interventions process put in place against generation and release of agents that could be harmful or injurious to 
Texila International Journal of Public Health

Volume 4, Issue 4, Dec 2016

personnel can prevent fatal outcome. This can protect this cadre of healthcare providers and reduce possible pollution of the environs were such facilities are located. In a study by Susan Q. Wilburn \& Gerry Eijkemans, 2013 - a WHO-ICN Collaboration on Preventing Needle stick Injuries among Healthcare Workers; it was documented that $28 \%$ of injuries often occurred during contact with medical waste bags ${ }^{2}$.

The 2006 World Health Report: "Working Together for Health on human resources" reported on a global shortage of health personnel which had reached crisis level in 57 countries, and called for the support and protection of the health workforce ${ }^{3}$. Importantly, health facilities should have implementable documents on prevention policies in place aimed at addressing immunizations for vaccine-preventable diseases such as HBV, isolation precautions to prevent exposures to infectious agents, management of health care personnel exposure to infected persons such as restrictions for exposed or infected health care personnel and provision of post-exposure prophylaxis. Such document should be read and endorsed by each member of staff or be read and interpreted in a language that personnel that cannot read and write understand. On the basis of documented nosocomial infection, Healthcare Providers are considered to be at substantial risk for acquiring or transmitting hepatitis B, influenza, Ebola, Lassa, HIV among other blood-borne pathogens ${ }^{4}$. Strategies aimed at the prevention and control of work related hazards occurring as a result of exposure could be referred to as occupational hygiene. Occupational hygiene has three main objectives - Ensuring safety and advancement of employee's health; environmental protection and contribution towards a safe and sustainable development. Occupational hygiene plays a key role as one of the best approaches towards protection of healthcare providers from occupational exposure. This is so because even though exposed individual can have the best diagnosis, treatment and cure for an occupational disease, that does not prevent further occurrences unless exposure to the etiological agent is halted. To achieve this, capacity building of personnel especially those in the low cadre on personal hygiene and healthcare waste management is very vital. In a study on epidemiology and management of occupational exposure to blood borne viral infections in resource poor settings: The case for availability of post exposure prophylaxis; O. Erhabor et al, 2007 demonstrated a prevalence of 53.9\% among house officers, $23.1 \%$ among resident doctors and $23.1 \%$ among Laboratory Scientists exposure to needle stick injury ${ }^{5}$. In another finding; Amira CO and Awobusuyi JO (2014) in a study on needle-stick injury (NSI) among health care workers in hemodialysis units in Nigeria: A multi-center study reported a prevalence of $24.5 \%$ within the last 12 months and $40.2 \%$ in their entire service career among participants. The report also had it that improper disposal of needles accounted for $30 \%$ of exposure $^{5}$. Interestingly, the forgoing also reported that only $37 \%$ of respondents reported their exposure to their unit head or designated officer in order to get medical advice ${ }^{6}$. This findings show that NSI is common among healthcare providers. Also, the level of understanding among healthcare providers on proper steps to take when exposure occurs seems limited. Importantly, the study population in above were mostly educated individuals (Doctors (37.3\%), Nurses 41.2\%), Technicians (13.7) while auxiliary staff constituted only $(7.8 \%)^{6}$. Needless to say that individuals working in hospital set ups in emerging countries of the world of which my country Nigeria is one, are predominantly at greater risk of infections from blood-borne pathogens due to high prevalence of such etiological agents coupled with limited basic personal protective equipment in such settings and also awareness on proper reporting and care for exposed persons. Soad A. Habiba et al (2012), in a research titled: Knowledge, attitude and behavior of health care workers regarding hepatitis B infection in primary health care, Kuwait, concluded that "Health care workers in primary health care showed high to partial levels of knowledge and attitudes, regarding hepatitis B virus infection and vaccination with important gaps which need to be strengthened especially among nonvaccinated group"”. From the foregoing, participants in the study are mostly educated persons ranging from Doctors, Nurses, Laboratory Scientist and technicians. Since such a findings could occur in this group of persons, one could just but imagine what would happen to the group under study - auxiliary healthcare workers. These are mostly lay workers with very 
minimal training if any on how to handle biological waste some of which carries improperly disposed sharps. In most hospital settings GH Wukari and GH Zing inclusive, hospital waste are easily spotted just at the back of the hospital premises. Young boys are at times also easily seen scavenging inside these waste to look for any salable recycle material. Unfortunately, inside those waste one can also see used syringes and needles and all manner of biological waste. In a study on Prevalence and Determinants of Occupational Exposures to Blood and Body Fluids among Health Workers in two Tertiary Hospitals in Nigeria, DimieOgoina et al., (2014) reported a prevalence of 85\% exposure among studied health workers reporting one or more type of exposures in the previous year ${ }^{8}$. Nigeria being one of the most populated developing nation in the world is said to be endemic for certain blood-borne infectious agents mainly hepatitis B virus (HBV), hepatitis C virus (HCV) and $\mathrm{HIV}^{8}$. Additionally, cases of Lassa fever have been reported in some states in Nigeria in January 2016 which includes Bauchi, Kano, Nassarawa, Niger, Rivers, Edo, Lagos, and Taraba ${ }^{9}$. Although there are a few research work within Nigeria that reports high prevalence of occupational exposures to blood and body fluids among health workers (Medubi et al 2006, Erhabor et al 2007; Isara et al 2012; Ansa et al, 2002); there remains dearth of information from research studies in the country that describe occurrence, prevalence and causes of these exposures among various cadres of health workers ${ }^{8}$.

The Centers for Disease Control and Prevention National Institute for Occupational Safety and Health (NIOSH) Alert on Preventing Needle stick Injuries in Health Care Settings recommends that health care setting should analyze needle stick and other sharps-related injuries in workplace to identify hazards and injury trends ${ }^{11}$. Findings from such analysis would provide idea early enough to re-assess or put in place preventive mechanisms.

It is recommended that Hospitals provide targeted interventions to increase awareness of the risks of needle stick injuries and reduce such injuries, A. Ruhi Toraman et al, $2011^{12}$

Undoubtedly, risk level of each exposed health care worker differs according to his/her profession, occupation and unit of work ${ }^{13 .}$ It is on records that health care providers such as nurses, physicians, dentists, orderlies and janitors carry the highest risk of being exposed to blood-borne pathogens ${ }^{13}$.

Although the Taraba State strategic health development plan $(2010 \text { - 2015 })^{14}$ reported that research for health in Taraba is almost non-existent; available documented findings indicate that in Taraba state, at a time HIV/AIDS prevalence rate is slowing down to a manageable level in other states of the federation, the rate is on the rise with a prevalence rate of $10.5 \%$ since 2012 in adults $15-49$ years ${ }^{15}$, the state ranks top in the north east and second highest in the country ${ }^{15}$. This high prevalence of HIV placed the State second to only River State with a prevalence of $15.2 \%{ }^{15}$. This rate is far higher than the National prevalence in same age group $3.5 \%{ }^{15}$. With this high prevalence, the likely risk of contaminated sharps used on patients in health facilities could be said to be high too, thereby posing a great danger to lay workers who may get pricked accidentally. Also, the prevalence of HBV is high in Taraba State (26.37\%) ${ }^{16}$. Again this is higher than the national prevalence of HBV $(13.6 \%)^{18}$. These documented evidences are genuine pointer to the high risk of infection from blood borne pathogens from accidental needle stick injuries and therefore calls for concern to health care workers. The prevalence of HCV in Taraba is $13 \%{ }^{16}$. The prevalence of HCV in Nigeria indicates variation from one region of the country to the other ${ }^{19}$

HCV prevalence range from $4.7-5 \%$ in Ilorin, to $5.3-6.6 \%$ in Enugu, to $11 \%$ in Ibadan, $13 \%$ in Taraba and $20 \%$ in Benin ${ }^{16,18}$. This also presence risk of likely infection be health care workers as a result of needle stick injuries with possibility of developing debilitating or fatal liver disease at some point in their lives and transmitting the infection to others unknowingly. From the 2006 national population census, Taraba has a population of 2,300,736 $1.643^{19}$. With high prevalence of HIV, HBV and HVC as enumerated above, the likely hood of danger from needle stick injuries to healthcare workers cannot be overemphasized. According to the Taraba State strategic health development plan (2010 2015), there is a dearth of quality health care workers in the state with a skewed distribution 
Texila International Journal of Public Health

Volume 4, Issue 4, Dec 2016

in favor of the urban dwellers ${ }^{14}$. This further compounds the problem since the mostly learned personnel ordinarily would likely migrate to the state capital leaving the less educated in facilities far away from the state capital, one could but say that lay workers in these two facilities stand the chance of getting exposed easily if not properly educated. World Health Organization (WHO) reported HBV to be a major cause of liver disease morbidity and mortality worldwide, accounting for over 360 million cases of chronic hepatitis and 620,000 deaths per a year ${ }^{20}$

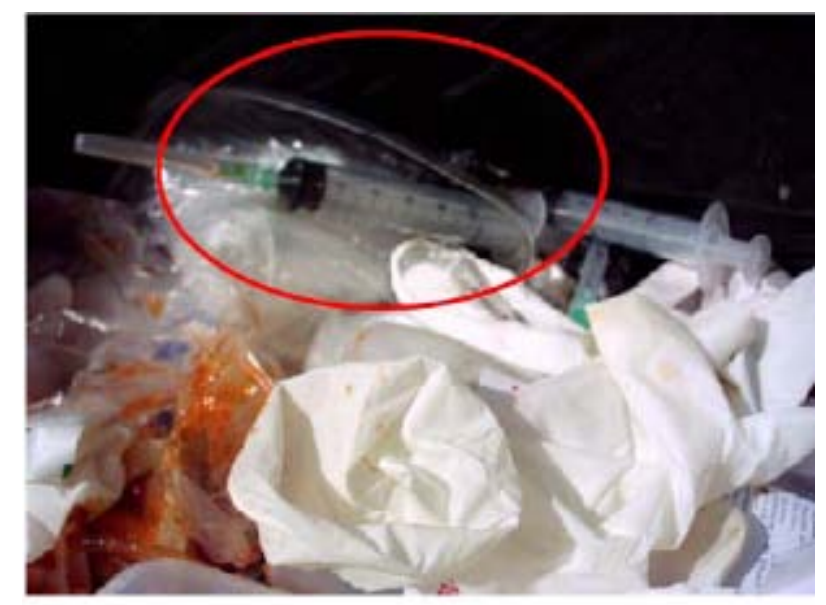

Figure 1. Hospital Biological Waste. No Segregation

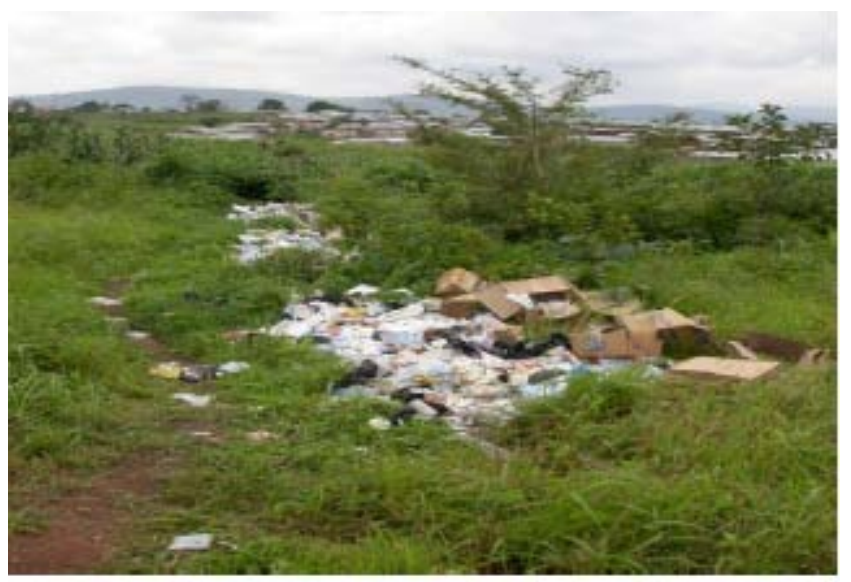

Figure 2. Hospital Waste. Improperly disposed

\section{Statement of the problem}

Although a number of safety measures and procedures have been instituted to halt the likelyhood of occupational health hazard on the safety and increased mortality/morbidity of healthcare providers, nevertheless; it has been documented that more and more healthcare workers suffer occupational hazards from needle stick injury due to exposure from occupational risk in health care settings ${ }^{10}$. Unfortunately, low cadre personnel including cleaners, ward orderly and laboratory attendants who handle hospital waste have minimal formal training on how to handle healthcare waste. Therefore, assessment of knowledge on injection safety and waste handling in this vulnerable group of individuals will provide firsthand information(s) aimed at instituting appropriate training and preventive measures in place.

\section{General objective}

This study aimed at assessing the level of knowledge of auxiliary healthcare providers on injection safety and biological waste handling in General Hospital (GH) Wukari and GH 
Zing, located in southern and northern senatorial districts of Taraba State, North Eastern Nigeria respectively.

\section{Specific objectives}

Description of respondents' socio-demographic status, assessment of frequencies of needle-stick injury among this group of healthcare workers, assess level of awareness on blood borne pathogens such as HBV, HCV, Lassa, HIV determine the awareness and attitude on management of post exposure and assess respondents on immunizations for vaccinepreventable diseases.

\section{Materials and method}

\section{Study sites}

General Hospital Wukari is located in the Southern senatorial district of Taraba state with a distance of about 209km away from the state capital Jalingo. GH Wukari, a 250 bed space facility is a secondary health facility established on April, $30^{\text {th }} 1962$. The hospital serves residence from both Benue and Taraba states being located at the border of these two states. The settlement could be said to be the headquarters of the Jukun speaking tribe in Taraba State since that is where the palace of the paramount Jukun chief and chairman Taraba traditional Council, The Akuka is located. Other tribes benefiting from the hospital include the Tivs, Fulanis', and some other minority tribes. Similarly, General Hospital Zing is also a secondary health facility with 100 bed space. The hospital is located in Zing LGA, Northern senatorial district of Taraba state. The distance is about $70 \mathrm{~km}$ away from Jalingo the state capital. Established in 1988, and serves people from Zing and other surrounding LGAs such as Yoro and Mayo Belwa in Adamawa State. The main language spoken is Mumuye. Zing also housed the palace of the paramount ruler of the Mumuye Chiefdom - the Kpanti Zing. Other tribes benefiting from this health facility include the Yandang and Fulanis'.

A descriptive cross-sectional survey conducted among auxiliary health workers comprising of ward orderlies, lab attendants, compound laborers, theater attendants and laundry personnel in the Month of June, 2016. Although these cadres may not be directly involve with patient care as the Doctors, Nurses, Laboratory Scientist and the Pharmacist, they come in contact with hospital generated wastes such as sharps and or soiled patient beddings in their routine work.

\section{Justifications for site selection}

General Hospital Wukari and General Hospital Zing are located at two different axis of Taraba State. Low cadre staff are not privilege to be transferred from one health facility to the other as their counterpart (example Doctors, Nurses, Laboratory Scientists and Pharmacists). Experience on how things are done from one facility to the other would therefore be absent among these groups. With this selection, a fair representation from lay healthcare personnel with relatively different sociocultural background was gotten.

\section{Data collection}

A semi structured interviewer/self-administered questionnaire was used for respondents that could read and write while the research assistant translate and explained the questions in language that respondent understands best for those that could not read and write. The questionnaire was developed using the Monkey Survey to generate the questions and a hard copy printed. Questions were based on CDC Advisory Committee (HICPAC) recommendations and guidelines for Healthcare Infection Control Practices and Environmental Infection Control in Health-Care Facilities ${ }^{21}$, customized to suit the purpose of this study. Demographic data such age, sex, cadre and work station were taken from each respondent. The purpose of the study was explained to each of the respondents and obtained their consent before completion of the questionnaire. The idea of developing my questionnaire in line with this guideline is to be able to obtain the relevant data from 
Texila International Journal of Public Health

Volume 4, Issue 4, Dec 2016

participants that would present a true reflection of the practice on ground by lay health care providers in these two facilities. Questionnaires were filled unanimously by respondents and returned at close of work day. Prior to commencement of the study, the questionnaire were field tested by administering to 15 auxiliary staff of First Referral Hospital MutumBiyu and minor corrections effected.

The study population was made up of a total of 68 persons comprising ward orderlies 42 (GH Wukari 25, GH Zing 17); lab attendants 5 (GH Wukari 3, GH Zing 2); compound laborers 9 (GH Wukari 5, GH Zing 4); theater attendants 5 (GH Wukari 3, GH Zing 2); and laundry personnel 7 (GH Wukari 4, GH Zing 3). Participants were identified with the use of random number. Ethical clearance was sought for and obtained from the Ethics Committee of the two General Hospitals where this work was carried out. Additionally, consent of each of the respondents concern was sought for and obtained before administering the questionnaire. Participants were given option not to answer any question they wish not to.

\section{Limitations}

Our in ability to cover all auxiliary healthcare workers in the two health facilities was a limitation to the study.

\section{Data analysis}

Data generated from the questionnaire were entered into spread sheet (Microsoft Excel software) and later moved to STATA version 13, a statistical software developed by StataCorp LP for analysis. Measures of central tendency (Means, medians, mode), standard deviations, and proportion were determined as applicable. Differences between groups were compared using Chi-square $\left(\chi^{2}\right)$ test. Correlation between percent knowledge and practice score was ascertained by Spearman correlation. Level of statistical significance was set at 95\% (P $\leq 0.05)$.

\section{Results}

Out of 75 questionnaires sent out, 69 representing 92.0\% response rate were received one of which was removed due to improper filling leaving us with 68 (90.7\%) properly filled questionnaires to work with.

Table 1. Respondents Demographic and service delivery point (n=68)

\begin{tabular}{llllll} 
SDPs & GH Wukari & & GH Zing & \multicolumn{2}{c}{$\begin{array}{l}\text { Total } \\
\text { (\%) }\end{array}$} \\
\hline & Male (\%) & $\begin{array}{l}\text { Female } \\
\text { (\%) }\end{array}$ & Male (\%) & $\begin{array}{l}\text { Female } \\
\text { (\%) }\end{array}$ & \\
\cline { 2 - 6 } Ward orderlies & 8 & 21 & 4 & 9 & $42(61.7)$ \\
Lab attendants & 2 & 1 & 0 & 2 & $5(7.4)$ \\
Com. Laborers & 4 & 1 & 3 & 1 & $9(13.2)$ \\
Theater Attendants & 2 & 1 & 2 & 0 & $5(7.4)$ \\
Laundry cleaners & 3 & 1 & 2 & 1 & $7(10.3)$ \\
\hline & $19(27.9)$ & $25(36.7)$ & $11(16.2)$ & $13(19.1)$ & $68(100)$ \\
\cline { 2 - 7 }
\end{tabular}

From the various service delivery points (SDPs) that responded in this survey, ward orderlies constituted the highest percentage (61.7\%), followed by compound laborers (13.2\%). Laundry sections came third with (10.3\%) while laboratory and theater attendants ties the fourth position with $7.4 \%$ each. Out of the total respondents in this survey, 40 representing 58.8 percent were from GH Wukari. While GH Zing constituted 28 representing 41.2 percent. Female folks from GH Wukari were 22(55.5\%) as against their male counterpart 18(45.0\%) out of participants from GH Wukari, while females from GH Zing were 16(57.1\%) as against their male counterpart 12(42.9\%) out of respondents from GH Zing. 
Table 2. Knowledge about blood borne pathogens $(n=37)$

\begin{tabular}{llllll} 
SDPs & GH Wukari & GH Zing & $\begin{array}{l}\text { Total } \\
(\%)\end{array}$ \\
\hline & Male & Female & Male & Female & \\
\hline Ward orderlies & 3 & 11 & 2 & 7 & $23(62.1)$ \\
Lab attendants & 2 & 1 & 0 & 2 & $5(100.0)$ \\
Com. Laborers & 1 & 0 & 1 & 0 & $2(5.4)$ \\
Theater Attendants & 2 & 1 & 2 & 0 & $5(100.0)$ \\
Laundry cleaners & 1 & 0 & 1 & 0 & $2(5.4)$ \\
\hline Total (\%) & $9(24.3)$ & $13(35.1)$ & $6(16.2)$ & $9(24.3)$ & $37(100)$ \\
\hline
\end{tabular}

From Table 2 above, only slightly over half of the respondents 37 (54.4\%) reported being knowledgeable about blood borne pathogens (HBV and HCV). All respondents from the laboratories and the theater in both facilities reported being aware of HBV, and HCV in addition to HIV which all participants reported to be aware of respectively. Respondents with least knowledge of HBV and HCV were from the compound laborers and the laundry workers (5.4\%) respectively.

Table 3. Have had Needle stick injury in last six months $(\mathrm{n}=32)$

\begin{tabular}{llllll} 
& GH Wukari & \multicolumn{3}{c}{ GH Zing } & \\
\cline { 2 - 5 } & Male & Female & Male & Female & Total (\%) \\
\hline Ward orderlies & 5 & 9 & 2 & 4 & $20(62.5)$ \\
Lab attendants & 1 & 1 & 0 & 2 & $4(12.5)$ \\
Com. Laborers & 2 & 1 & 3 & 0 & $3(9.4)$ \\
Theater Attendants & 1 & 1 & 1 & 0 & $3(9.4)$ \\
Laundry cleaners & 1 & 0 & 1 & 0 & $2(6.3)$ \\
\hline & 10 & 12 & 7 & 6 & $32(100)$ \\
\hline
\end{tabular}

Of the 68 AHCWs who took part in this study, a high proportion 32/68 (47.0\%) reported to have had needle stick injury within the last six months (table 3). Exposure to needle stick injury cuts across all service delivery points.

Level of HBV, HCV Knowledge Vs Route of transmission

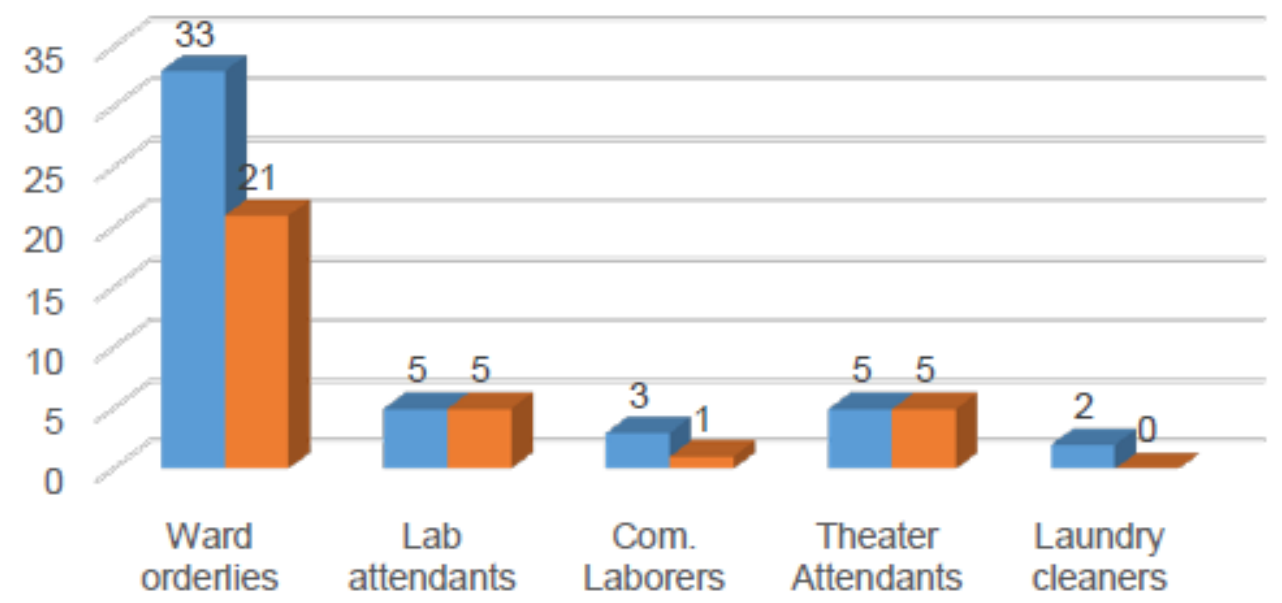

- Knowledge of HBV $\quad$ Route of Transmission of HBV

Chart 1. Level of HBV Knowledge Vs Route of transmission 
Texila International Journal of Public Health

Volume 4, Issue 4, Dec 2016

On average, the general level of knowledge of the respondents in various service delivery points to HBV and HCV seems very high (chart 1). However; although a high number of ward orderlies (33/42, 78.6\%) are aware of the HBV and HCV, only a half (21/42, 50\%) are aware of the route of transmission. Similarly, only $1 / 3$ of compound laborers who claimed to be aware recorded knowledge of route of transmission while none of the 2 laundry workers who reported awareness of HBV/HCV knows the route of transmission.

\section{Exposed AHCWs Vs Those who accessed PEP}

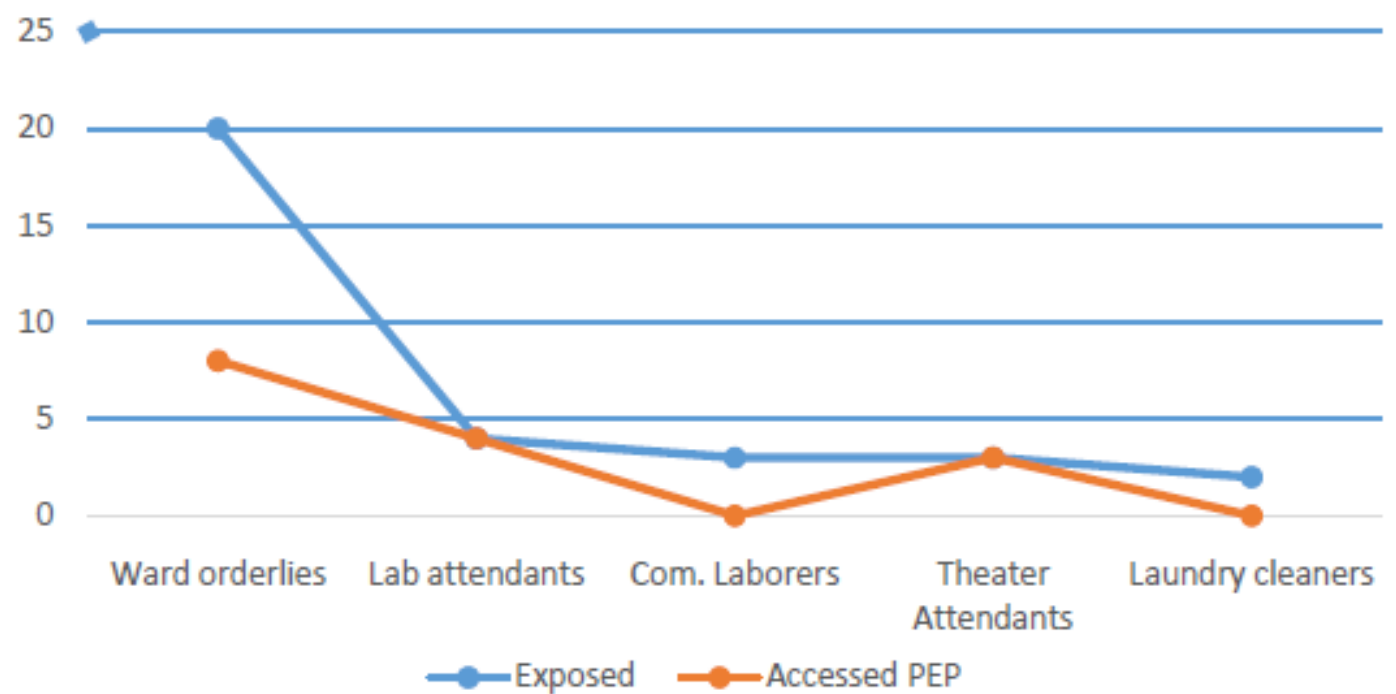

Chart 2: Exposed AHCWs Vs those who accessed PEP

In assessing the level of needle-prick injury accident management (NPIAM) and post exposure prophylaxis (PEP) among respondents (Chart 2), only Theater and Lab attendants seems to be more knowledgeable about PEP as all exposed persons $(5 / 5,5 / 5)$ in that order accessed PEP. Less than half of Ward orderlies 8/20 (40\%) of those who had needle stick injury in the last six months accessed PEP while none of the exposed persons among the compound cleaners and laundry workers accessed PEP.

\section{Usage of gloves and rain boots (PPE)}

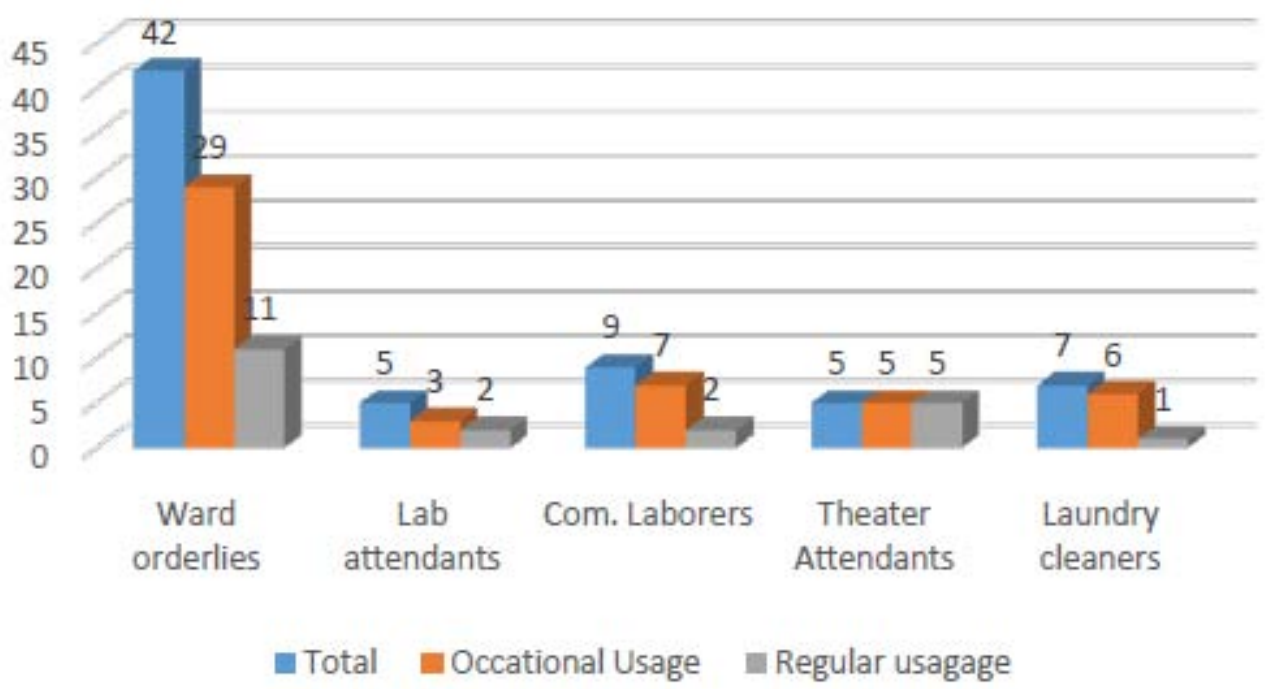

Chart 3. Usage of personal protective equipment (PPE) 
Chart 3 represents participant's usage of PPE. Only theater attendants had total compliance to regular usage of PPE. Out of 42 Ward orderlies who responded, 29 (60.1\%) and $11 / 42(26.2 \%)$ used hand gloves occasionally and regularly respectively, while Laboratory attendants reported $3 / 5(60 \%)$ and $2 / 5(40 \%)$ occasional and regular usage in that order. Compound laborers reported 7/9 (77.8\%) and 22.2\%) occasional and regular usage. Similarly, Laundry workers reported 6/7 (85.7\%) and 1/7 (14.3\%) occasional and regular usage respectively.

\section{Discussion}

Consequent to the potential impact of occupational health hazard on safety, increased mortality and morbidity of health care providers, various precautionary safety measures have been instituted, however healthcare workers are continually exposed to occupational risk factors in health care settings from blood borne pathogens. Biosafety procedures are critical as long as health care delivery is concerned and the service delivery of health workforce is certainly mandatory. Protective strategies aimed at prevention of occupational hazards in the lay workers and adherence to safety strategies is sacrosanct to ensure a safe and healthy worker force in the health industry.

Findings from this study reveals that all the participants seems to be aware of HIV. This is likely so because in both facilities, comprehensive HIV program has been on since 2007. Awareness about HIV is very high in the two facilities under study. However; knowledge of other blood borne disease causing agent including HBV and HCV seems to be low. Only about a half of the participants 37/68 (54.4\%) exhibited good knowledge of other blood borne pathogens (HBV and $\mathrm{HCV}$ ). This findings corroborated the report on Injection safety assessment in Nigeria, 2004 conducted by John Snow Incorporated through funding from USAID which concluded that level of knowledge of health care providers about injection safety was limited ${ }^{23}$. Occupational exposure to sharp objects could lead to transmission of infections among healthcare providers. This usually occurs as a result of deficiency in the knowledge of healthcare providers about guidelines on hospital infection control procedures. Interaction with these lay healthcare workers who takes care of the hospital waste revealed knowledge gap on waste segregation and even disposal. This knowledge gap was clearly seen on visitation to some of the dump sites as shown in the portrait. Due to lack of incinerator in the two facilities, wastes are disposed untreated in landfills while burning of wastes in the open within the hospital premises was common in the two hospitals.

Instituting educational activities to healthcare providers, ancillary personnel inclusive aimed at educating them on infection control measures will curb this. However, the gap on knowledge and practice of infection control among healthcare givers has to be established. Of all the 68 AHCWs that took part in this study, 32/68 (47.1\%) reported to have had needled stick injury in the past six months. This might not be unconnected with frequent usage of needle in Nigerian health institutions with improper disposal method in place. This finding agrees with findings on Injection safety assessment in Nigeria, 2004 conducted by John Snow Incorporated through funding from USAID in which it was reported that "a very high burden of injection was found prevailing in Nigeria”23. There is no proper disposal of sharp wastes in most health institutions in Nigeria. This can be easily seen behind hospital buildings where they are either dumped in a pit or discarded in openings where young boys could be seen scavenging for re-useable items. Such was the finding in the two facilities under study. Worthy of note is the issue of post exposure prophylaxis. In all, only 15/32 representing $46.9 \%$ of the respondents (about one half) of the individuals who reported to have had needle stick injury in the last six months reported to have accessed post exposure prophylaxis (PEP). This study suggests that personal safety measures by auxiliary healthcare workers in GH Wukari and GH Zing was being handled with laxity due to dearth of knowledge on the consequences of such exposure. This findings corroborate the findings of Oguamanam et al 2014 who reported an alarming finding that despite the fact that about two thirds of respondents knew of post exposure prophylaxis, only a quarter of those who had needle prick 
Texila International Journal of Public Health

Volume 4, Issue 4, Dec 2016

injury accessed needle prick injury and management of post exposure prophylaxis and concluded that "the level of knowledge was high but poor in Post-Exposure Prophylaxis and Needle-prick injury accident management (NPIAM) protocol and register for post-exposure prophylaxis" ${ }^{23}$. With the exception of theater attendants, the attitude of respondents on usage of personal protective equipment showed a negative perspective. Very low percentages of the AHCWs reported regular usage of hand gloves despite their continuous exposure to biological waste in the course of their work $(26.2 \%, 40 \%, 22.2 \%$ and $14.3 \%)$ of WOs, Las, CL and LW respectively. Rain boots and utility gloves are supposed to be used regularly by the Compound laborers due to their exposure to sharps and other biological waste but was not the case. This may not be unconnected with the level of awareness in this category of health care providers.

Essential medical equipment and commodities for infection prevention and control (IPAC) are supposed to be made available for efficient service delivery by healthcare workers. Personal protective equipment including biosafety gloves, face mask, lab coats, boots and proper waste containers such as sharp boxes, color-coded bins and bin linings are rarely provided or not at all. In situations where such items are provided, HCWs are not willing to use them. Waste not being segregated was readily observed in the two facilities. Neither of the two facilities had incinerator hence waste are dumped outside behind the hospital.

\section{Conclusion}

We conclude that there is low level of knowledge on needle stick injury (NSI), biological waste handling and poor knowledge/attitude towards PEP among auxiliary healthcare providers in GH Wukariand GH Zing.

\section{Recommendations}

The following recommendations are hereby made to ensure health and safety of auxiliary healthcare workers at GH Wukari and GH Zing at their service deliver points:

1. There is need for capacity building and regular knowledge update of low cadre personnel on injection safety and biological hospital waste management. During Continuous Medical Education (CME), sessions could be made for presentations in languages that are easily understood by the lay personnel. This will enshrine good injection safety and hospital waste management among AHCWs.

2. The Hospital management could make provision for and awareness creation on HBV vaccine and make it mandatory for healthcare providers

3. Lay personnel should be educated on detail contacts and steps to be taken for Post Exposure Management.

4. The hospital management should make available commodities such as utility hand gloves, rain boots etc. for cleaners to avoid exposure to biological wastes.

5. Similar research could be carried out in other healthcare facilities of the state to present a wider findings in this important cadre of personnel in Taraba health facilities

\section{References}

[1]. Amira CO, Awobusuyi JO (2014). Needle-stick injury among health care workers in hemodialysis units in Nigeria: a multi-center study. Int J Occup Environ Med 2014; 5:1-8.

[2]. Centers for Disease Control and Prevention: Exposure to Blood: What Healthcare Personnel Need to Know. 2003, Available: http://www.cdc.gov/HAI/pdfs/bbp/Exp_to_Blood.pdf. Accessed June 2016 www.cdc.gov/niosh Accessed $17^{\text {th }}$ July, 2016

[3]. CDC MMWR / November 25, 2011 / Vol. 60 / No. 7

[4]. Dimie Ogoina, Kemebradikumo Pondei, Babatunde Adetunji, George Chima, Christian Isichei, and Sanusi Gidado (2014). Prevalence and Determinants of Occupational Exposures to Blood and Body Fluids Among Health Workers in Two Tertiary Hospitals in Nigeria Afr J Infect Dis. 8(2): 5054. 
[5]. Ejiofor O S, Emechebe G O, Igwe W C, Ifeadike C O, Ubajaka C F. Hepatitis C virus infection in Nigerians. Niger Med J 2010;51:173-6

[6]. https://en.wikipedia.org/wiki/Occupational_safety_and_health Accessed $13^{\text {th }}$ June, 2016

[7]. http://www.tandfonline.com/doi/abs/10.1179/oeh.2004.10.4.451 Accessed $13^{\text {th }}$ June, 2016

[8]. http://www.who.int/occupational_health/topics/hcworkers/en/. Accessed $14^{\text {th }}$ June, 2016

[9]. http://deolaonline.com/factsheets-on-lassa-fever/. Accessed $14^{\text {th }}$ June, 2016

[10]. https://naca.gov.ng/article/hivaids-prevalence-rate Accessed $18^{\text {th }}$ July, 2016

[11]. http://en.wikipedia.org/wiki/List_of_Nigerian_states_by_population Accessed $13^{\text {th }}$ July, 2016

[12]. http://www.cdc.gov/mmwr/preview/mmwrhtml/rr5210a1.htm. Accessed $14^{\text {th }}$ July, 2016

[13]. http://www.who.int/immunization/topics/hepatitis/en/ Accessed $14^{\text {th }}$ July, 2016

[14]. http://nigeria.usembassy.gov/uploads/images/McLyWtfPi8-

VIVCnFmfaLQ/Injection_Safety_Assessment_in_Nigeria.pdf Accessed $15^{\text {th }}$ July, 2016

[15]. Karwowski W, Jang RL, Rodrick D, Peter MQ, Cronin SN. Self-evaluation of biomechanical task demands, work environment and perceived risk of injury by nurses: a field study. Occup Ergon. 2005;5:13-27.

[16]. Musa B, Bussell S, Borodo M M, Samaila A A, Femi O L. Prevalence of hepatitis B virus infection in Nigeria, 2000-2013: A systematic review and meta-analysis. Niger J ClinPract 2015;18:163-72

[17]. O. Erhabor, O.A. Ejele and C.A. Nwauche (2007). Epidemiology and management of occupational exposure to blood borne viral infections in resource poor settings: The case for availability of post exposure prophylaxis. Nigerian Journal of Clinical Practice, June 2007 Vol 10(2): 100-104

[18]. OS Elkanah, AL Okoye, OE Debby-Sambo. Prevalence of Hepatitis-B Surface Antigen among Blood Donors in Jalingo, Taraba State, Nigeria Nigerian Journal of Parasitology Vol 34, No 2 (2013

[19]. OguamanamOkezieEnwere, Kevin ChiekulieDiwe 2014: Knowledge, perception and practice of injection safety and healthcare waste management among teaching hospital staff in south east Nigeria: an intervention study Pan Afr Med J. 2014; 17: 218.

[20]. RuhiToraman, FatmaBattal, Kirstin Ozturk\&BetulAkcin (2011) Sharps Injury Prevention for Hospital Workers, International Journal of Occupational Safety and Ergonomics, 17:4, 455-461, DOI: 10.1080/10803548.2011.11076908

[21]. Soad A. HabibaGhadeer A. Alrashidi, Afaf E.M. Al-otaibi, Ghizayel R. Almutairi, Gamal Makboul and Medhat K. El-Shazl (2012): Knowledge, attitude and behavior of health care workers regarding hepatitis B infection in primary health care, Kuwait. Greener Journal of Medical Sciences Vol. 2 (4), pp. 077-083

[22]. Taraba State strategic health development plan (2010 - 2015) 